\title{
Comparison of variations in cornea after one-handed and two-handed coaxial phacoemulsification
}

This article was published in the following Dove Press journal:

Clinical Ophthalmology

\author{
Panpan $\mathrm{Li}^{1,2}$ \\ Yujian Zhang' \\ Lihua Kang \\ Yu Guan' \\ Jian $\mathrm{Wu}^{\prime}$ \\ Huaijin Guan' \\ 'Department of Ophthalmology, \\ Affiliated Hospital of Nantong \\ University, Nantong, China; \\ ${ }^{2}$ Department of Ophthalmology, \\ The First People's Hospital of \\ Nantong, Nantong, China
}

\begin{abstract}
Purpose: To compare corneal variations in patients undergoing one-handed and two-handed coaxial phacoemulsification.

Setting: Eye Institute, Affiliated Hospital of Nantong University, Nantong, China.

Design: Prospective consecutive nonrandomized comparative cohort study.

Methods: Patients with cataracts were subject to one-handed (one-handed group) or twohanded coaxial phacoemulsification (two-handed group). Intraoperative phaco parameters and postoperative outcomes, such as visual acuity, surgically induced astigmatism (SIA), corneal volume, central corneal thickness, and corneal endothelial cell counts/size were compared.

Results: No significant differences in the intraoperative phaco parameters were noted between the 2 groups. At postoperative week 1, visual outcomes were significantly improved in the onehanded compared with the two-handed group (all $P<0.05$ ). Corneal volume, central corneal thickness, and average cell size were significantly decreased in the one-handed group compared with two-handed group (all $P<0.05$ ), but the aforementioned differences were ameliorated at 1 month and 3 months postoperatively. Endothelial cell loss was significantly decreased in the one-handed group compared with the two-handed group at any follow-up point (all $P<0.05$ ). No significant differences in SIA on the anterior surface were noted between the 2 groups. SIA on the posterior surface was significantly decreased in the one-handed group compared with the two-handed group at 1 week postoperatively $(P=0.043)$ but not at 1 month and 3 months postoperatively.
\end{abstract}

Conclusion: One-handed phacoemulsification has the advantages of less trauma to the cornea and better early visual outcomes compared with the two-handed technique.

Keywords: one-handed, phacoemulsification, corneal volume, central corneal thickness, corneal endothelial cell

\section{Introduction}

Most cataract surgeries are currently performed using the phacoemulsification technique, which is under constant refinement to reduce sight-threatening adverse events and achieve better functional postoperative outcomes as a result of improvements in aspheric, multifocal, and toric optical designs in intraocular lenses. ${ }^{1,2}$ However, transient postoperative corneal edema affects the initial functional results. ${ }^{3,4}$ Corneal edema is closely correlated with intraoperative corneal endothelial injury, ${ }^{5}$ which is associated with anterior chamber depth (ACD), lens density, phacoemulsification technique, ultrasound time and energy used, intraoperative mechanical and heat injury, and turbulent flow of irrigating solution. ${ }^{6-8}$ Currently, corneal endothelial injury after phacoemulsification is generally assessed by specular microscopy in
Correspondence: Jian Wu; Huaijin Guan Department of Ophthalmology, Affiliated Hospital of Nantong University, 20 Xisi

Road, Nantong 226000, China

$\mathrm{Tel}+8613901483006$;

+86I3809088972

Email wujian_fy@163.com;

guanhuaijinleye@I26.com
Clinical Ophthalmology 2018:12 I8I5-1822

(c) (1) (2) ๑ 2018 Li et al. This work is published and licensed by Dove Medical Press Limited. The full terms of this license are available at https//wwr.dovepress.com/terms.php cc) hereby accept the Terms. Non-commercial uses of the work are permitted without any further permission from Dove Medical Press Limited, provided the work is properly attributed. For permision for commercial use of this work, please see paragraphs 4.2 and 5 of our Terms (https://www. doverperess.com/terms.php). 
terms of changes in endothelial cell density (ECD) and cell morphology. ${ }^{9,10}$ Given that endothelial cellular injury alters the pumping activity of this corneal layer and subsequently increases stromal hydration, ${ }^{11}$ corneal volume (CV) is also considered indicative of complete endothelial cell function in the area. ${ }^{12}$ Pentacam includes pachymetry software that enables clinicians to measure the central corneal thickness (CCT) and CV within a 3.0, 5.0, 7.0, or $10.0 \mathrm{~mm}$ circle around the central cornea. ${ }^{13}$

Currently, 2 types of coaxial phacoemulsification techniques are available. One-handed phacoemulsification is performed through the main incision only, whereas twohanded phacoemulsification is performed through the main incision with the help of a chopper through a corneal side port. ${ }^{13-15}$ To our knowledge, limited studies have compared corneal changes between these 2 phacoemulsification techniques. The main objective of our study was to compare variations in $10 \mathrm{~mm} \mathrm{CV}, \mathrm{CCT}$, and corneal endothelial cell in cases undergoing one-handed and two-handed coaxial phacoemulsification.

\section{Methods}

This prospective nonrandomized comparative cohort study comprised patients with age-related cataract (ARC) who chose and underwent one-handed phacoemulsification (100 eyes) at the Department of Ophthalmology, Affiliated Hospital of Nantong University, Jiangsu, China from August 2016 to September 2017. The eye conditions, such as axial length, ACD, nuclear opalescence (NO), lens thickness, and intraocular pressure (IOP), were matched with patients undergoing two-handed phacoemulsification (100 eyes). The study was performed in accordance with the ethical principles of the Declaration of Helsinki and was approved by the hospital's ethics committee. All patients provided written informed consent after receiving a full explanation of the study. Patients undergoing phacoemulsification were divided into 2 groups based on the type of the surgical technique: one-handed technique with a $2.4-\mathrm{mm}$ clear corneal incision (CCI) (one-handed group) or two-handed technique with a $2.4 \mathrm{~mm}$ CCI and a $1.0 \mathrm{~mm}$ corneal side port (twohanded group).

Lens Opacities Classification System III was used for cataract classification. ${ }^{16}$ Inclusion criteria included the following: 1) patients with $\mathrm{NO} \leq 3 ; 2$ ) normal anterior segment and fundus examination; 3 ) no history of intraocular surgery or injury; and 4) pupil dilation at the preoperative was at least $7 \mathrm{~mm}$. Exclusion criteria included the following: 1) cataract other than ARC;2) corneal scars or opacities and other ocular disease that might affect visual outcomes; 3 ) the diameter of the nucleus was $>6 \mathrm{~mm}$; 4) patients failing to undergo phacoemulsification, or the intraocular lens was not successfully placed in the capsular bag; and 5) patients failing to attend postoperative appointments.

All operations were performed under topical anesthesia with $0.5 \%$ proparacaine hydrochloride (Novartis International AG, Basel, Switzerland) by the same experienced surgeon (HG). Pupillary dilation was achieved with the instillation of 1 drop of $0.5 \%$ compound tropicamide (Santen, Osaka, Japan) every 10 minutes until the pupil diameter was $>7 \mathrm{~mm}$ before surgery. In all cases, sodium hyaluronate gel (Bausch \& Lomb, Bridgewater, NJ, USA) was used as an ophthalmic viscosurgical device (OVD), and balanced salt solution (BSS) was used as the infusion fluid.

In the one-handed group, a 2.4-mm single-plane CCI was created at a $135^{\circ}$ position under the guidance of Verion (Alcon Laboratories, Inc., Fort Worth, TX, USA) with a diamond keratome. Continuous curvilinear capsulorhexis (CCC) was performed with capsular forceps under the protection of an OVD. After CCC, hydrodissection and hydrodelineation were performed. In preparation for phacoemulsification, the surgeon then inserted a phacoemulsification needle (Centurion, Alcon) with the right hand, and microscopic tweezers fixed the eyeball with the left hand (Figure 1).

In the two-handed group, a 2.4-mm single-plane CCI was created at $135^{\circ}$ position under the guidance of Verion as the main corneal incision. CCC was performed with capsular forceps under the protection of an OVD. After CCC, hydrodissection and hydrodelineation were performed. A corneal side port was created at $20^{\circ}$ position with a $1.0 \mathrm{~mm}$ diamond keratome. In preparation for phacoemulsification, the surgeon

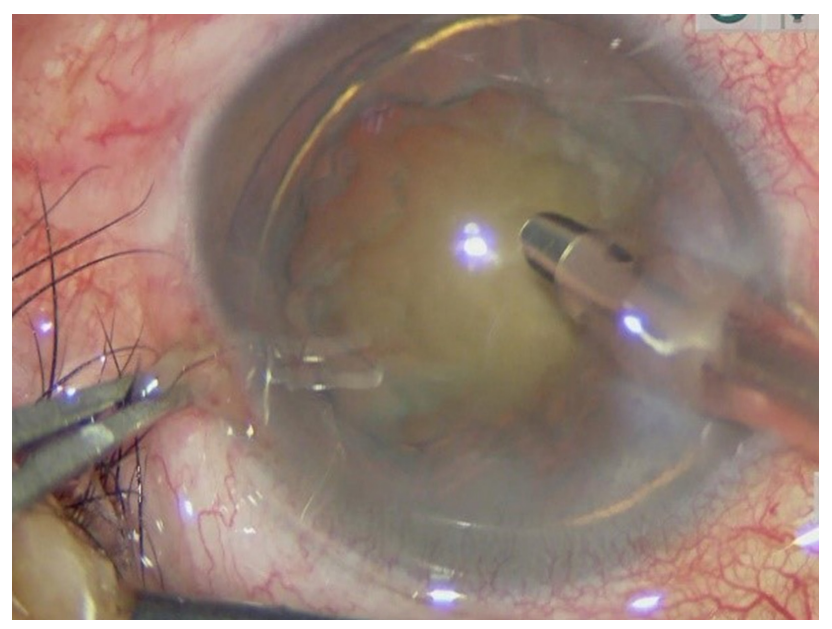

Figure I One-handed coaxial phacoemulsification technique. 
then inserted a phacoemulsification needle through the main corneal incision, and a manual chopper was inserted through the corneal side port (Figure 2).

All phacoemulsification was performed using the phacoemulsification machine (Centurion, Alcon) in the Ozil Intelligent Phaco mode. The ultrasound and fluidic settings were as follows: bottle height, $105 \mathrm{~cm}$; power, $60 \%$; vacuum, $500 \mathrm{mmHg}$; aspiration flow, $32 \mathrm{cc} / \mathrm{min}$. A foldable monofocal IOL (PY-60AD; HOYA, Tokyo, Japan) was implanted in the capsular bag with an injector. At the end of the surgery, the clear corneal wound was hydrated with BSS, and no sutures were applied.

Intraoperative phaco parameters were recorded as follows: ultrasonic total time, cumulative dissipated energy (CDE), total fluid usage, and total surgical time (the time between the creation and closure of the corneal incision by stromal hydration. ${ }^{17}$

All patients underwent complete ophthalmologic measurements, and these measurements were performed preoperatively and at follow-up appointments at 1 week, 1 month, and 3 months postoperatively. Visual acuity included uncorrected and corrected distance visual acuity (UDVA and CDVA). Biometry, such as axial length, ACD, and lens thickness, were performed using a non-contact optical lowcoherence reflectometer Lenstar (LS900; Haag-Streit, Koniz, Switzerland). CV within the central 10-mm zone, CCT, and keratometry readings were obtained using Pentacam (70700; Oculus, Wetzlar, Germany). Central endothelial cell count/ size was measured using a noncontact specular microscope (EM-3000; Tomey, Aichi, Japan). Surgically-induced astigmatism (SIA) was analyzed by vector analysis according to the Alpins method. ${ }^{18}$

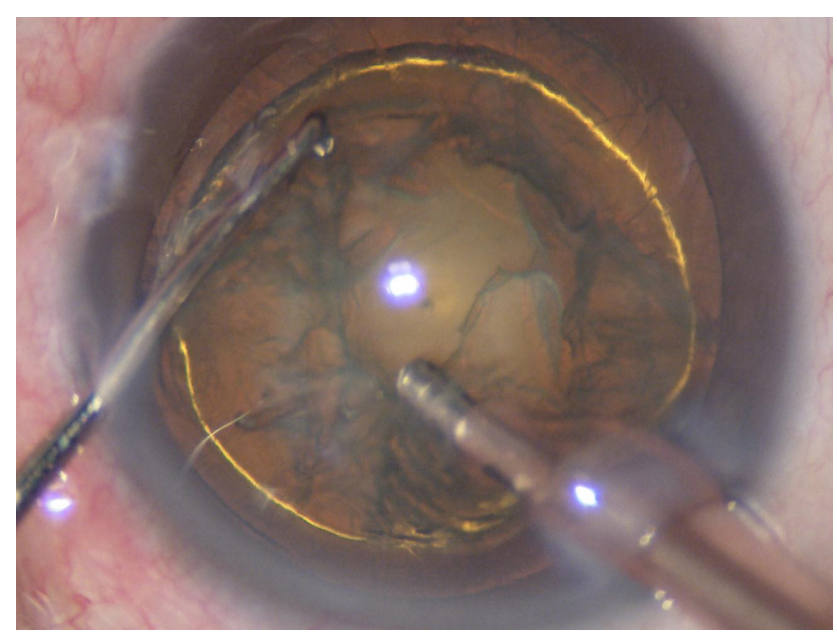

Figure 2 Two-handed coaxial phacoemulsification technique.
Statistical analysis was performed using SPSS for Windows software (version 22; SPSS, Inc.). Homoscedasticity of the samples was studied using Levene's test. For the comparison of one-handed and two-handed group data, the independent $t$-test or the Mann-Whitney $U$ test was used. For the comparison of pre- and postoperative data, the pairedsamples $t$-test was used. The level of statistical significance was $P<0.05$.

\section{Results}

The study evaluated 200 eyes (124 right and 86 left) of 176 patients (119 females and 57 males). Patients' demographics and preoperative ophthalmic measurements are provided in Table 1. No significant differences in age, NO, axial length, ACD, lens thickness, and IOP were noted between the 2 groups (all $P>0.05$ ).

The surgical parameters in both groups are summarized in Table 2. No significant differences were noted between the 2 groups regarding ultrasound total time, $\mathrm{CDE}$, total fluid usage, and total surgical time (all $P>0.05$ ).

Table 3 displays the visual acuity and SIA on the anterior and posterior surfaces of the cornea between the 2 groups. Compared with baseline, UDVA and CDVA were significantly improved at all follow-up points in both groups (all $P<0.001$ ). At postoperative 1 week, UDVA and CDVA in the one-handed group were significantly improved compared with the two-handed group (all $P<0.05$ ). However, the aforementioned differences were ameliorated at 1 and 3 months postoperatively (all $P>0.05$ ). The between-group difference in SIA on the anterior surface was not statistically significant at any follow-up point (all $P>0.05$ ). At postoperative 1 week, the SIA on posterior surface in the one-handed group was significantly decreased compared with

Table I Patient demographics and baseline parameters

\begin{tabular}{llll}
\hline Parameters & \multicolumn{2}{l}{ Mean \pm SD } & P-value \\
\cline { 2 - 3 } & One-handed & Two-handed & \\
\hline Patients/eyes & $93 / 100$ & $91 / 100$ & - \\
Sex (female/male) & $62 / 31$ & $62 / 29$ & $0.762^{\dagger}$ \\
Eye (right/left) & $61 / 39$ & $57 / 43$ & $0.566^{\dagger}$ \\
Age (years) & $66.64 \pm 6.83$ & $67.96 \pm 6.37$ & $0.159^{*}$ \\
NO (LOCS III) & $1.93 \pm 0.58$ & $1.88 \pm 0.62$ & $0.530^{*}$ \\
Axial length (mm) & $23.40 \pm 1.26$ & $23.66 \pm 1.35$ & $0.169 *$ \\
ACD (mm) & $3.17 \pm 0.39$ & $3.20 \pm 0.37$ & $0.652^{*}$ \\
Lens thickness (mm) & $4.15 \pm 0.64$ & $4.27 \pm 0.58$ & $0.19 I^{*}$ \\
IOP (mmHg) & $16.13 \pm 2.09$ & $15.92 \pm 1.98$ & $0.467^{*}$ \\
\hline
\end{tabular}

Notes: *Independent $t$-test; $P<0.05$ was considered statistically significant; ${ }^{\dagger}$ MannWhitney $U$ test.

Abbreviations: NO, nuclear opalescence; LOCS III, Lens Opacities Classification System III; ACD, anterior chamber depth; IOP, intraocular pressure. 
Table 2 Intraoperative parameters of the 2 groups

\begin{tabular}{llll}
\hline Parameters & \multicolumn{2}{l}{ Mean \pm SD } & P-value \\
\cline { 2 - 3 } & One-handed & Two-handed & \\
\hline CDE & $5.15 \pm 3.70$ & $4.77 \pm 3.65$ & $0.457^{*}$ \\
U/S total time $(\mathrm{s})$ & $27.84 \pm 19.6 \mathrm{I}$ & $23.62 \pm 16.55$ & $0.10 \mathrm{I}$ \\
Total fluid usage $(\mathrm{mL})$ & $42.57 \pm 12.83$ & $42.3 \mathrm{I} \pm 14.99$ & $0.895^{*}$ \\
Total surgical time $(\mathrm{s})$ & $349.98 \pm 58.85$ & $345.07 \pm 46.4 \mathrm{I}$ & $0.508^{*}$ \\
\hline
\end{tabular}

Note: *Independent $t$-test; $P<0.05$ was considered statistically significant.

Abbreviations: CDE, cumulative dissipated energy; U/S total time, ultrasound total time.

the two-handed group $(P=0.043)$ but not at 1 and 3 months postoperative (all $P>0.05$ ).

Table 4 presents the $10-\mathrm{mm} \mathrm{CV}, \mathrm{CCT}$, and central endothelial cell count/size of the 2 groups. In both groups, the mean 10-mm CV (Figure 3) was significantly increased at 1 week (all $P<0.001$ ) and 1 month postoperative (all $P<0.05)$, the values returned to preoperative levels at 3 months postoperative (all $P>0.05$ ). The between-group difference was statistically significant at 1 week postoperative $(P=0.006)$ but not at 1 month $(P=0.563)$ and 3 months postoperative $(P=0.290)$. In both groups, the mean CCT (Figure 4) was significantly thicker at 1 week postoperative (all $P<0.001$ ). However, the values returned to preoperative levels at 1 month (all $P>0.05$ ) and 3 months postoperative (all $P>0.05)$ in both groups. The between-group difference was statistically significant at 1 week postoperative $(P=0.046)$ but not at 1 month $(P=0.868)$ and 3 months postoperative
$(P=0.774)$. In both groups, the mean ECD (Figure 5) was significantly decreased postoperatively (all $P<0.001$ ), and no significant difference was observed between the 2 groups at any follow-up point (all $P>0.05$ ). In both groups, the mean percentages of hexagonal cell $(\mathrm{HEX} \%)$ were significantly decreased postoperatively (all $P<0.001$ ), and no significant differences were observed between the 2 groups at any follow-up point (all $P>0.05$ ). In both groups, the average cell size (Save) (Figure 6) was significantly increased at all follow-up points (all $P<0.001$ ). At 1 week postoperative, Save in the one-handed group was significantly decreased compared with the two-handed group $(P=0.047)$. However, the aforementioned differences were ameliorated at 1 month and 3 months postoperative (all $P>0.05$ ).

\section{Discussion}

The main objective of our study was to compare corneal variations in patients undergoing one-handed and two-handed coaxial phacoemulsification. To limit bias, we only included patients with ARC and the two groups exhibited similar preoperative characteristics, such as age, axial length, ACD, cataract density, lens thickness, and IOP, which were associated with intraoperative corneal endothelial injury. Since onehanded phacoemulsification is suitable for soft-to-moderate lenses, ${ }^{19}$ we only included patients with $\mathrm{NO} \leq 3$.

In one-handed phacoemulsification, after sculpting, a full-thickness groove is created centrally and progressing

Table 3 Visual acuity and SIA

\begin{tabular}{|c|c|c|c|c|c|}
\hline \multirow[t]{2}{*}{ Parameters } & One-handed & $P$-value ${ }^{a}$ & Two-handed & $P$-value ${ }^{a}$ & $P$-value ${ }^{b}$ \\
\hline & \multicolumn{2}{|l|}{ Mean \pm SD } & \multicolumn{3}{|l|}{ Mean \pm SD } \\
\hline \multicolumn{6}{|l|}{ UDVA (logMAR) } \\
\hline Preop & $0.69 \pm 0.14$ & - & $0.72 \pm 0.15$ & - & $0.25 I^{*}$ \\
\hline I week postop & $0.10 \pm 0.12$ & $<0.00 I^{* *}$ & $0.15 \pm 0.12$ & $<0.001 * *$ & $0.012^{*}$ \\
\hline I month postop & $0.10 \pm 0.11$ & $<0.00 I^{* *}$ & $0.12 \pm 0.11$ & $<0.001 * *$ & $0.110 *$ \\
\hline 3 month postop & $0.10 \pm 0.08$ & $<0.00 I^{* *}$ & $0.11 \pm 0.09$ & $<0.00 I^{* *}$ & $0.283^{*}$ \\
\hline \multicolumn{6}{|l|}{ CDVA (logMAR) } \\
\hline Preop & $0.58 \pm 0.14$ & - & $0.60 \pm 0.18$ & - & $0.347^{*}$ \\
\hline I week postop & $0.02 \pm 0.10$ & $<0.001 * *$ & $0.05 \pm 0.10$ & $<0.001 * *$ & $0.03 I^{*}$ \\
\hline I month postop & $0.00 \pm 0.10$ & $<0.001 * *$ & $0.01 \pm 0.09$ & $<0.00 I^{* *}$ & $0.465^{*}$ \\
\hline 3 month postop & $0.00 \pm 0.09$ & $<0.00 I^{* *}$ & $0.0 \mathrm{I} \pm 0.08$ & $<0.00 I^{* *}$ & 0.868 \\
\hline \multicolumn{6}{|l|}{ SIA (anterior) } \\
\hline I week postop & $1.07 \pm 0.64$ & - & $1.15 \pm 0.70$ & - & $0.437^{*}$ \\
\hline I month postop & $0.88 \pm 0.54$ & - & $0.87 \pm 0.43$ & - & $0.935^{*}$ \\
\hline 3 month postop & $0.75 \pm 0.44$ & - & $0.77 \pm 0.38$ & - & $0.715^{*}$ \\
\hline \multicolumn{6}{|l|}{ SIA (posterior) } \\
\hline I week postop & $0.44 \pm 0.38$ & - & $0.55 \pm 0.36$ & - & $0.043^{*}$ \\
\hline I month postop & $0.24 \pm 0.18$ & - & $0.26 \pm 0.18$ & - & $0.48 I^{*}$ \\
\hline 3 month postop & $0.22 \pm 0.14$ & - & $0.24 \pm 0.16$ & - & $0.388 *$ \\
\hline
\end{tabular}

Notes: *Independent t-test; **Paired-samples $t$-test; $P^{a}=$ comparison between preop and postop; $P^{a}<0.05$ was considered statistically significant; $P^{b}=$ comparison of both groups, $P^{\mathrm{b}}<0.05$ was considered statistically significant.

Abbreviations: UDVA, uncorrected distance visual acuity; log-MAR, logarithm of the minimum angle of resolution; preop, preoperative; postop, postoperative; CDVA, corrected distance visual acuity; SIA, surgically-induced astigmatism. 
Table $4 \mathrm{CV}, \mathrm{CCT}$ and corneal endothelial cell counts/size

\begin{tabular}{|c|c|c|c|c|c|}
\hline \multirow[t]{2}{*}{ Parameters } & \multirow{2}{*}{$\frac{\text { One-handed }}{\text { Mean } \pm \text { SD }}$} & \multirow[t]{2}{*}{$P$-value ${ }^{a}$} & \multirow{2}{*}{$\frac{\text { Two-handed }}{\text { Mean } \pm \text { SD }}$} & \multirow[t]{2}{*}{$P$-value ${ }^{a}$} & \multirow[t]{2}{*}{$P$-value ${ }^{b}$} \\
\hline & & & & & \\
\hline \multicolumn{6}{|l|}{$\mathrm{CV}\left(\mu \mathrm{m}^{3}\right)$} \\
\hline Preop & $60.87 \pm 3.32$ & - & $60.40 \pm 3.00$ & - & $0.290 *$ \\
\hline I week postop & $63.36 \pm 3.80$ & $<0.001 * *$ & $64.80 \pm 3.45$ & $<0.00 I^{* *}$ & $0.006^{*}$ \\
\hline I month postop & $61.50 \pm 3.31$ & $0.018^{* *}$ & $61.80 \pm 3.78$ & $<0.00 I^{* *}$ & $0.563^{*}$ \\
\hline 3 month postop & $60.74 \pm 3.11$ & $0.183 * *$ & $60.43 \pm 3.13$ & $0.140 * *$ & $0.290 *$ \\
\hline \multicolumn{6}{|l|}{ CCT $(\mu \mathrm{m})$} \\
\hline Preop & $529.81 \pm 31.23$ & - & $527.96 \pm 29.75$ & - & $0.668 *$ \\
\hline I week postop & $543.33 \pm 28.20$ & $<0.001^{* *}$ & $551.69 \pm 29.15$ & $<0.001^{* *}$ & $0.04 I^{*}$ \\
\hline I month postop & $531.23 \pm 31.67$ & $0.192 * *$ & $531.98 \pm 31.93$ & $0.066 * *$ & $0.868 *$ \\
\hline 3 month postop & $528.31 \pm 31.70$ & $0.201 * *$ & $529.80 \pm 32.63$ & $0.412 * *$ & $0.774^{*}$ \\
\hline \multicolumn{6}{|l|}{$\mathrm{ECD}\left(/ \mathrm{mm}^{2}\right)$} \\
\hline Preop & $2,539.05 \pm 235.33$ & - & $2,570.60 \pm 262.28$ & - & $0.372 *$ \\
\hline I week postop & $2,366.0 \mathrm{I} \pm 237.70$ & $<0.001 * *$ & $2,363.32 \pm 259.94$ & $<0.00 I^{* *}$ & $0.939 *$ \\
\hline I month postop & $2,358.5 \mathrm{I} \pm 228.16$ & $<0.00$ I** & $2,356.07 \pm 250.66$ & $<0.00 I^{* *}$ & $0.943^{*}$ \\
\hline 3 month postop & $2,358.1 I \pm 229.33$ & $<0.00 I^{* *}$ & $2,354.28 \pm 259.59$ & $<0.00 I^{* *}$ & $0.912 *$ \\
\hline \multicolumn{6}{|l|}{ ECL (\%) } \\
\hline I week postop & $6.82 \pm 3.39$ & - & $8.08 \pm 3.31$ & - & $0.009 *$ \\
\hline I month postop & $7.05 \pm 4.22$ & - & $8.28 \pm 4.28$ & - & $0.046^{*}$ \\
\hline 3 month postop & $7.06 \pm 4.37$ & - & $8.37 \pm 4.85$ & - & $0.045^{*}$ \\
\hline \multicolumn{6}{|l|}{ HEX\% } \\
\hline Preop & $40.27 \pm 6.19$ & - & $40.42 \pm 5.60$ & - & $0.858 *$ \\
\hline I week postop & $39.60 \pm 6.17$ & $<0.00 I^{* *}$ & $39.84 \pm 5.34$ & $<0.00 I^{* *}$ & $0.788^{*}$ \\
\hline I month postop & $39.36 \pm 5.79$ & $<0.00 I^{* *}$ & $39.27 \pm 5.86$ & $<0.00 I^{* *}$ & $0.913^{*}$ \\
\hline 3 month postop & $39.18 \pm 6.12$ & $<0.00 I^{* *}$ & $39.28 \pm 6.48$ & $<0.001$ & $0.911 *$ \\
\hline \multicolumn{6}{|l|}{ Save $\left(\mu \mathrm{m}^{2}\right)$} \\
\hline Preop & $408.62 \pm 63.58$ & - & $397.7 I \pm 51.80$ & - & $0.185^{*}$ \\
\hline I week postop & $571.75 \pm 184.92$ & $<0.001^{* *}$ & $627.11 \pm 205.51$ & $<0.00 I^{* *}$ & $0.047^{*}$ \\
\hline I month postop & $510.44 \pm 113.54$ & $<0.00 I^{* *}$ & $521.22 \pm 120.87$ & $<0.00 I^{* *}$ & $0.516^{*}$ \\
\hline 3 month postop & $458.06 \pm 67.79$ & $<0.00 I^{* *}$ & $468.83 \pm 72.29$ & $<0.00 I^{* *}$ & $0.278^{*}$ \\
\hline
\end{tabular}

Notes: *Independent $t$-test; **Paired samples $t$-test; $P^{a}=$ comparison between preop and postop, $P^{a}<0.05$ was considered statistically significant; $P^{b}=$ comparison of both groups, $P^{\mathrm{b}}<0.05$ was considered statistically significant.

Abbreviations: CV, corneal volume; preop, preoperative; postop, postoperative; CCT, central corneal thickness; ECD, endothelium corneal density; ECL, endothelium corneal loss; HEX\%, percentages of hexagonal cell; Save, average cell size.

peripherally, so a half-lens diameter groove is obtained. The lens is then rotated, and another half-diameter groove is created. The basic process (cut, rotate, cut, remove, rotate, cut, and remove) is repeated. ${ }^{9}$ In the entire process, the phaco tip was completely buried in the nucleus, blocked the energy release, and reduced heat injury. In addition, nuclear fragments and/or other mechanical trauma to the corneal endothelium were significantly decreased. During

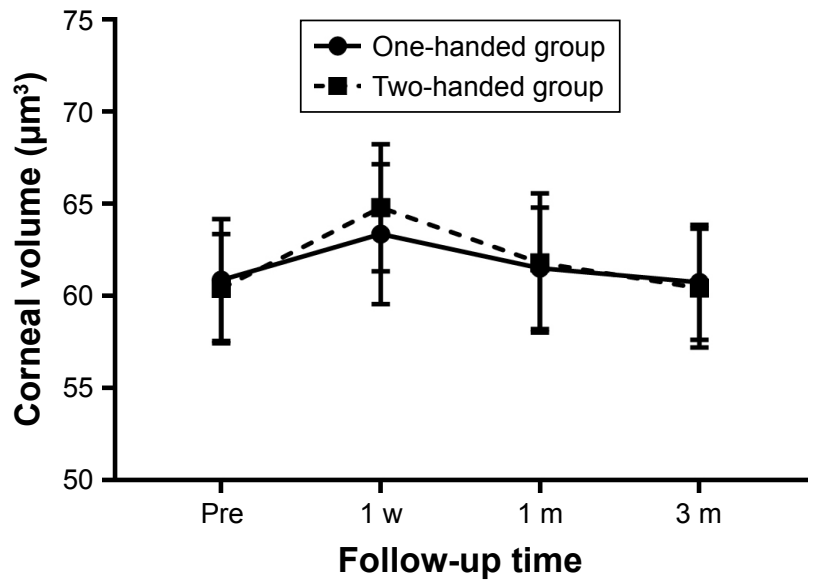

Figure 3 Change in corneal volume over time.

Abbreviations: w, week; m, months; pre, preoperative.

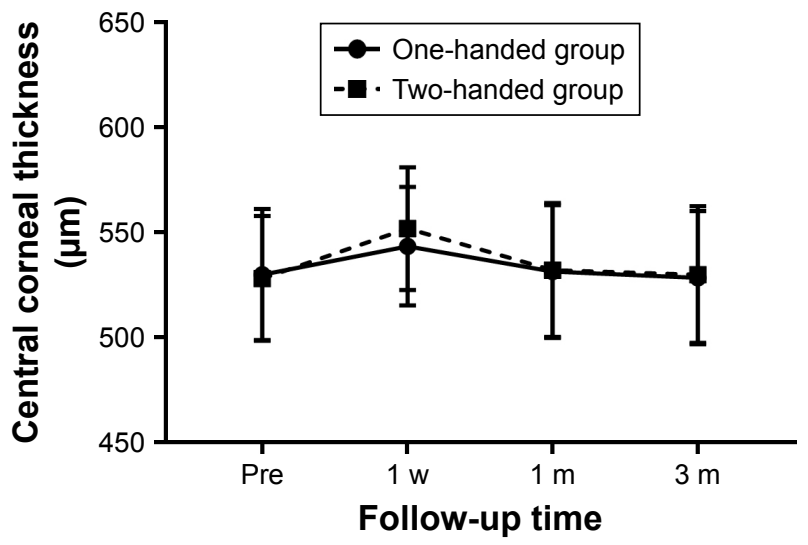

Figure 4 Change in central corneal thickness over time. Abbreviations: w, week; m, months; pre, preoperative. 


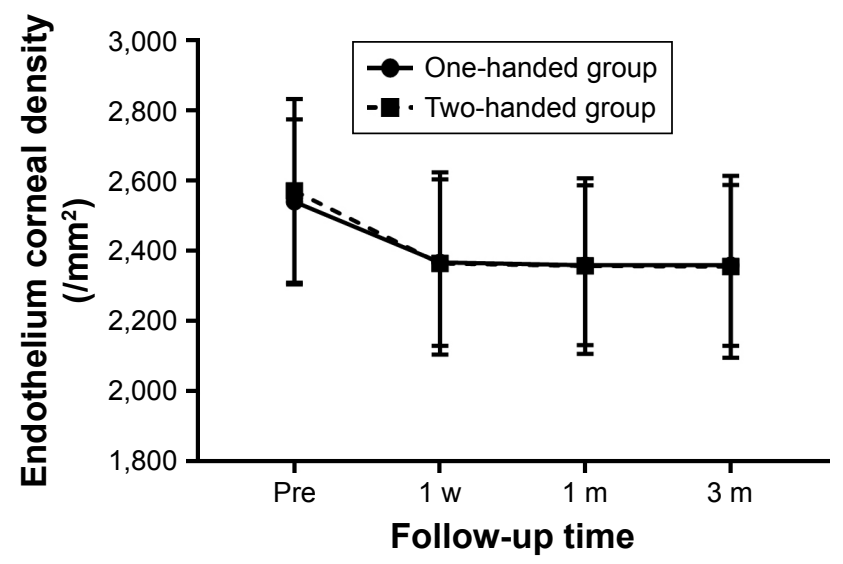

Figure 5 Change in endothelium corneal density over time. Abbreviations: $\mathrm{w}$, week; $\mathrm{m}$, months; pre, preoperative.

one-handed phacoemulsification, hydrodissection plays a significant role. There is a single instrument (phacoemulsification tip) to rotate the nucleus, and a wave of fluid opens a space between the lens capsule and cortex. Hydrodissection, when performed well, greatly facilitates one-handed phacoemulsification. In order to perform a perfect hydrodissection, pupil dilation at the preoperative was at least 7 $\mathrm{mm}$, the diameter of capsule crevasse was $6 \mathrm{~mm}$. The main disadvantage of the technique is the decreased controllability of the nucleus without the help of a chopper, especially in hard or large nuclei. In our study, the ultrasound total time and CDE were slightly increased in the one-handed group compared with the two-handed group, but the differences were not statistically significant.

At present, corneal endothelial injury after phacoemulsification is generally assessed by specular microscopy in terms of changes in corneal endothelial cells. In our study, no significant difference in ECD was noted between 2 groups at any follow-up point, but the mean ECL in the one-handed

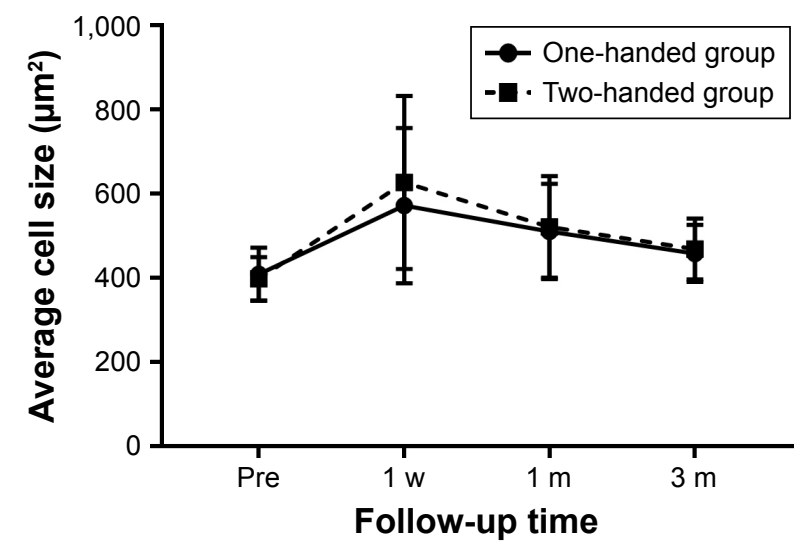

Figure 6 Change in average cell size over time. Abbreviations: w, week; m, months; pre, preoperative. group was significantly decreased compared with the two-handed group. Kawahara et $\mathrm{al}^{13}$ reported no significant difference in ECL between the 2 groups. In his study, the patients had nuclear senile cataracts grade 2-4 per EmeryLittle classification, which is slightly harder than our patients, and one-handed phacoemulsification is suitable for soft-tomoderate lenses. ${ }^{19}$

Analysis of cell size is also a sensitive indicator of endothelial damage. The intercellular space becomes larger during the healing period. ${ }^{10}$ After surgical trauma, the undamaged endothelial cells undergo morphologic changes to fill the cell-free areas and restore normal function. Once endothelial repair is complete, the intercellular space is reduced to its previous size, and the endothelial layer is restored. ${ }^{10}$ In our study, the average cell size in the one-handed group was significantly decreased compared with the two-handed group at 1 week postoperative, confirming that one-handed coaxial phacoemulsification technique has the advantages of reduced trauma to corneal endothelium cells.

Given that endothelial cellular injury alters the pumping activity of this corneal layer, resulting in increased stromal hydration, ${ }^{11} \mathrm{CV}$ and CCT are currently considered indicative of complete endothelial cell function in the area. ${ }^{7}$ In our study, both 10-mm CV and CCT were increased in the two-handed compared with the one-handed group at 1 week but not at 1 and 3 months postoperative. However, in both groups, no significant difference in ECD was noted postoperatively between the 2 groups. Our results reveal the discrepancy between the degree of alteration in ECD and $\mathrm{CV}$. The increase in $\mathrm{CV}$ after phacoemulsification is not necessarily due to corneal endothelial damage. Several other causes, such as tissue edema resulting from heat injury in the corneal stroma, might also increase the volume. ${ }^{12}$ Suzuki et $\mathrm{al}^{12}$ reported that $10 \mathrm{~mm} \mathrm{CV}$ remained significantly increased compared with preoperative values 3 months after surgery. In our study, at 3 months postoperative, $10 \mathrm{~mm}$ $\mathrm{CV}$ levels were restored to previous levels. Given that we only included early stages of cataracts in this study, corneal endothelial swelling caused by phacoemulsification may not have lasted for 1 month.

$\mathrm{HEX} \%$ was important parameters of the corneal endothelium, high $\mathrm{HEX} \%$ was also seen as an indicator of a healthy corneal endothelium. ${ }^{20} \mathrm{HEX} \%$ in our research was about $40 \%$, which was lower than other research (HEX\% was about 50\% to $60 \%),{ }^{20,21}$ the difference between the measuring instruments was an important reason. In addition, individual differences are also an important factor, hypertensive patients, high IOP, and history of outdoor work might decrease endothelial cell 
count 1 , enlargement of healthy endothelial cells and reduction in their hexagonality occur in cases of decreasing number of endothelial cells. ${ }^{21-24}$ In our research, the HEX\% in 2 groups were significantly decreased postoperatively. Further studies should be undertaken to reduce the decrease of $\mathrm{HEX} \%$ after phacoemulsification by adjusting IOP (or bottle height) and temperature of infusion fluid.

The early improvement of early visual acuity is highly pursued for successful cataract surgery. In our study, UDVA and CDVA in the one-handed group were statistically improved compared with the two-handed group at 1 week postoperatively, and these conditions were associated with corneal trauma.

SIA is influenced by the incision size, location, corneal radius, and corneal thickness. ${ }^{25-28}$ Kawahara et al $^{13}$ reported no statistically significant difference between the one-handed and two-handed groups regarding SIA at 1 month postoperatively. In our study, only the between-group difference in SIA on posterior corneal surface was statistically significant at 1 week postoperatively, which might be largely associated with the early influence of corneal edema and not only due to the effect of corneal side port. Thus, the aforementioned differences were ameliorated at 1 and 3 months postoperative.

\section{Conclusion}

Our results indicated that one-handed coaxial phacoemulsification has the advantage of reduced trauma to the cornea. Moreover, the corneal side port in two-handed cataract surgery has no effect on the SIA after corneal edema is eliminated. However, the limitation of our study is that the study only included $\mathrm{NO} \leq 3$, and patients with hard lenses were excluded. Therefore, our conclusion is only limited cataract patients with a soft-to-moderate nucleus.

\section{Acknowledgments}

The authors have no proprietary or financial interest in any of the materials or methods described herein. This study was supported by the Jiangsu Province Science and Technology Department of Social Development Major Projects-Key Diseases Standardization Diagnosis and Treatment Projects (BE2016669) and Nantong Frontier and Key Technologies of Social Innovation of the People Livelihood Programs (MS22015072). This work was supported by the Jiangsu Province Science and Technology Department of Social Development Major Projects-Key Diseases Standardization Diagnosis and Treatment Projects (BE2016669), Nantong Frontier and Key Technologies of Social Innovation of the People Livelihood Programs (MS22015072).

\section{Disclosure}

The authors report no conflicts of interest in this work.

\section{References}

1. Stein JD, Grossman DS, Mundy KM, Sugar A, Sloan FA. Severe adverse events after cataract surgery among medicare beneficiaries. Ophthalmology. 2011;118(9):1716-1723.

2. Javitt JC, Steinert RF. Cataract extraction with multifocal intraocular lens implantation: a multinational clinical trial evaluating clinical, functional, and quality-of-life outcomes. Ophthalmology. 2000;107(11): 2040-2048.

3. Lundberg B, Jonsson M, Behndig A. Postoperative corneal swelling correlates strongly to corneal endothelial cell loss after phacoemulsification cataract surgery. Am J Ophthalmol. 2005;139(6):1035-1041.

4. Yu Y, Chen X, Hua H, Wu M, Lai K, Yao K. Comparative outcomes of femtosecond laser-assisted cataract surgery and manual phacoemusification: a six-month follow-up. Clin Exp Ophthalmol. 2016;44(6): 472-480.

5. Yuen KS, Cheng AC, Chan WM. Postoperative corneal swelling correlates strongly to corneal endothelial cell loss after phacoemulsification cataract surgery. Am J Ophthalmol. 2005;140(6):1171.

6. Hayashi K, Manabe S, Yoshimura K, Kondo H. Corneal endothelial damage after cataract surgery in eyes with pseudoexfoliation syndrome. J Cataract Refract Surg. 2013;39(6):881-887.

7. Walkow T, Anders N, Klebe S. Endothelial cell loss after phacoemulsification: relation to preoperative and intraoperative parameters. J Cataract Refract Surg. 2000;26(5):727-732.

8. Wilczynski M, Supady E, Loba P, Synder A, Palenga-Pydyn D, Omulecki W. Comparison of early corneal endothelial cell loss after coaxial phacoemulsification through $1.8 \mathrm{~mm}$ microincision and bimanual phacoemulsification through $1.7 \mathrm{~mm}$ microincision. $J$ Cataract Refract Surg. 2009;35(9):1570-1574.

9. WaringGO,Bourne WM,EdelhauserHF, KenyonKR. The cornealendothelium. Normal and pathologic structure and function. Ophthalmology. 1982;89(6):531-590.

10. Tanev I, Tanev V, Kanellopoulos AJ. Nanosecond laser-assisted cataract surgery: Endothelial cell study. J Cataract Refract Surg. 2016; 42(5):725-730.

11. Calabuig-Goena M, López-Miguel A, Marqués-Fernández V, Coco-Martín MB, Iglesias-Cortiñas D, Maldonado MJ. Early Changes in Corneal Epithelial Thickness after Cataract Surgery - Pilot Study. Curr Eye Res. 2016;41(3):311-317.

12. Suzuki H, Oki K, Takahashi K, Shiwa T, Takahashi H. Functional evaluation of corneal endothelium by combined measurement of corneal volume alteration and cell density after phacoemulsification. J Cataract Refract Surg. 2007;33(12):2077-2082.

13. Kawahara A, Kurosaka D, Yoshida A. Comparison of surgically induced astigmatism between one-handed and two-handed cataract surgery techniques. Clin Ophthalmol. 2013;7:1967-1972.

14. John T. Corneal sensation after small incision, sutureless, one-handed phacoemulsification. J Cataract Refract Surg. 1995;21(4):425-428.

15. Pacifico RL. Divide and conquer phacoemulsification. One-handed variant. J Cataract Refract Surg. 1992;18(5):513-517.

16. Tan AC, Loon SC, Choi H, Thean L. Lens Opacities Classification System III: cataract grading variability between junior and senior staff at a Singapore hospital. J Cataract Refract Surg. 2008;34(11): 1948-1952.

17. Can I, Takmaz T, Yildiz Y, Bayhan HA, Soyugelen G, Bostanci B. Coaxial, microcoaxial, and biaxial microincision cataract surgery: prospective comparative study. J Cataract Refract Surg. 2010;36(5): 740-746.

18. Alpins NA. Vector analysis of astigmatism changes by flattening, steepening, and torque. J Cataract Refract Surg. 1997;23(10):1503-1514. 
19. He S. Diseases of the lens. 2nd ed. China: People's Medical Publishing House; 2013:268-272. Available from: https://detail.tmall.com/item. htm?id=542866802622. Accessed August 7, 2018. Chinese.

20. Li Y, Fu Z, Liu J, Li M, Zhang Y, Wu X. Corneal Endothelial Characteristics, Central Corneal Thickness, and Intraocular Pressure in a Population of Chinese Age-Related Cataract Patients. J Ophthalmol. 2017; 2017:9154626.

21. Storr-Paulsen A, Norregaard JC, Ahmed S, Storr-Paulsen T, Pedersen TH. Endothelial cell damage after cataract surgery: divide-and-conquer versus phaco-chop technique. J Cataract Refract Surg. 2008;34(6): 996-1000.

22. Higa A, Sakai H, Sawaguchi S, et al. Corneal endothelial cell density and associated factors in a population-based study in Japan: the Kumejima study. Am J Ophthalmol. 2010;149(5):794-799.

23. Bourne WM. Corneal endothelium - past, present, and future. Eye Contact Lens. 2010;36(5):310-314.
24. Joyce NC. Proliferative capacity of corneal endothelial cells. Exp Eye Res. 2012;95(1):16-23.

25. Hashemi H, Khabazkhoob M, Soroush S, Shariati R, Miraftab M, Yekta A. The location of incision in cataract surgery and its impact on induced astigmatism. Curr Opin Ophthalmol. 2016;27(1):58-64.

26. Luo L, Lin H, He M, Congdon N, Yang Y, Liu Y. Clinical evaluation of three incision size-dependent phacoemulsification systems. Am J Ophthalmol. 2012;153(5):831-839.

27. Woo SJ, Lee JH. Effect of central corneal thickness on surgically induced astigmatism in cataract surgery. J Cataract Refract Surg. 2003; 29(12):2401-2406.

28. Theodoulidou S, Asproudis I, Kalogeropoulos C, Athanasiadis A, Aspiotis M. Corneal diameter as a factor influencing corneal astigmatism after cataract surgery. Cornea. 2016;35(1):132-136.
Clinical Ophthalmology

\section{Publish your work in this journal}

Clinical Ophthalmology is an international, peer-reviewed journal covering all subspecialties within ophthalmology. Key topics include: Optometry; Visual science; Pharmacology and drug therapy in eye diseases; Basic Sciences; Primary and Secondary eye care; Patient Safety and Quality of Care Improvements. This journal is indexed on

\section{Dovepress}

PubMed Central and CAS, and is the official journal of The Society of Clinical Ophthalmology (SCO). The manuscript management system is completely online and includes a very quick and fair peer-review system, which is all easy to use. Visit http://www.dovepress.com/ testimonials.php to read real quotes from published authors. 